\title{
The Application of Folklore Implication in the Inheritance of Folk Art
}

\author{
Yongfeng Guo \\ Ningxia Normal University, Guyuan, Ningxia, 756000
}

Keywords: Folk Cultural Meaning; Folk Art; Inheritance

\begin{abstract}
In the process of the creation of folk art, a large number and extensive application of the symbol, so that people's aesthetic culture of the aesthetic understanding and familiar with, to some extent makes people's aesthetic taste gradually convergence. In view of this, this article first elaborated the folk cultural meaning in the folk art inheritance the important significance, after the detailed analysis of the folk cultural meaning in the folk art heritage application.
\end{abstract}

\section{Introduction}

The symbolic symbol in the process of inheritance and continuation by the influence of folk culture, its stable characteristics make folk art more standardized, and ultimately to ensure that the folk art theme, shape, color and other artistic elements to extend and develop. Therefore, it should be through the expression of folk culture symbolic symbol to protect and inherit folk art, people will be familiar with and loved cultural symbols used in folk art works, in order to improve the work of the degree of circulation and appreciation, in order to eventually achieve the inheritance and the purpose of the development of folk art works.

The rapid development of modern social economy, making the commercialization and industrialization of the wave swept the world, for our folk culture heritage and carry forward a huge challenge, many folk cultures and folk art heritage is facing a stagnant situation. Chinese relevant designers should adhere to and widely use the cultural and cultural implication, while the government should also increase the support and protection of folk cultural implication, materialist dialectics that outside the external and internal factors, things can be developed. In the process of inheriting folk art, the reference to the symbol can be used as internal factors, the government's help as external factors to make it develop. External factors are the conditions for the development of things, internal factors is the basis of development, if the folk cultural meaning is not reflected in the modern design work, then the government no matter how much effort to support and protection are also of no avail, therefore, in the inheritance and continuation folk culture implied in the process, it should first ensure that it has been a lot of and profound application, while the government to give support to ensure that the traditional folk culture and folk art can be a long history, never disappear.

\section{The Meaning of Folk Culture in the Folk Art Heritage of the Important Significance}

Folk art will be the culmination of folk culture and continue to inherit and continue, making the traditional folk culture in today's rapid development of the times still occupy a place. The relationship between folk art and folklore influences the various artistic factors such as the modeling and creative ideas of folk art. The characteristics of folk art are natural and honest, and it is difficult to reflect this in other art forms. Arouse people's pursuit of the original art and longing. Therefore, in folk art in the heritage and carry forward the folk cultural meaning, one of its important significance is the ancient art concept and shape inherited down.

In the creation of folk art works, the object of its performance will always symbolize a symbol of the symbol, in the creation of works before they come out, these symbols have existed and the creator will be used in the creation of works, as a result of the expression out of some meaning and profound meaning. Therefore, the folk art in the patterns, patterns, a variety of themes, color and 
other moral are given to them, the symbolic symbol of human and nature, human and social complex relationship between them, their profound connotation far than they show the image more richer. The characteristics of the symbolic symbols are geographically related, and they are collectively inherited and are collectively recognized to be more easily passed down. Folk art in the color, theme and pattern, and so every element is just right to represent a symbol of the symbol, has a certain symbolic meaning. Therefore, in folk art in the inheritance and carry forward the folk cultural meaning of another important significance is to continue the essence of ancient art down.

Social background and life will have an important impact on folk culture and folk art, folk cultural meaning through the folk art works to performance and materialization, its unique aesthetic form shown. The various elements and structures of folk art are standardized and constrained in the symbolic symbols of folk culture, which makes the characteristics of folk art aesthetic more obvious. So most of the creators of folk art will be in accordance with this art norms create, over time the formation of an era of artistic characteristics and personality. In order to make better use of the moral symbols in folk culture, many creators in the choice must have the idea of convergence, from the traditional folk art and modern folk culture contains the meaning of the design and other elements of the characteristics of Analysis, found that it always retains the inheritance of artistic features. There are many traditional folk art works have been popular, but in the long river was forgotten and lost, and get to the cause, found that these folk art works in the performance of folk culture implied in the process of limitations. Folk art works expressed in the folk cultural meaning is based on the specific era of the background and then, when these times the background no longer exists, these works if there is no far-reaching moral implications, then it is likely to be slowly forgotten and lost. Therefore, the folk cultural implication in folk art in the transmission of another important significance is to allow folk art to better continuation and development.

\section{The Application of Folk Culture in the Inheritance of Folk Art}

In Chinese folk art is still widely circulated art has paper-cut, which plays a very important role in folk art, paper cutting is an independent artistic expression, but also for other folk art modeling made a reference. Such as shadow play, embroidery, cloth toys are on the basis of the paper cut out, so that paper is the basis of folk art. So far, many aspects of our lives are still applied to the paper-cut patterns and other factors, the performance of the elegant, festive folk culture. For example, in the marriage, the Spring Festival, the relocation and other festive days will be used to paper cutting, which can beautify the room and gift as gifts to friends and family. In the mosquito nets, pillows, shoes or clothing to join the embroidery patterns have exorcism evil spirits of the implication, similar to this cultural meaning also exists in various forms of paper cutting, such as in the application of marriage, because there are Feng Peony Saying, while the pomegranate has many children's meaning, so people will be phoenix and peony paper-cut pattern through a special way into the pomegranate, the meaning of more than blessed. At the same time, with the lion roll hydrangea, mandarin ducks and other water to the meaning of the newly married couple love each other, with a doll riding a lotus carved bird map meaning full of clothing, unicorn child meaning early child and so on. In addition, there are sick dolls, Lao Huo doll, Zhong Kui ghosts and so used to exorcise evil spirits.

In many of the daily necessities of the symbol, by familiar with its connotation and the background, can be interpreted and more reasonable reference. Such as non-toxic map of the five poison refers to the snake, scorpion, toad, mussel and gecko, the general will be embroidered in the children wearing vests, dumplings and shoes and hats, if you see children's clothes embroidered with five Poison map, do not be puzzled, this is to remove the evil, the children wear embroidered with five poisonous clothes can be a good way to avoid the infestation of venom, to poison the attack mode to ensure the safety of children. In the Miao and other ethnic minorities in the embroidery is also very easy to find the pattern of butterflies, this is because the Miao people to the butterfly as a mascot, it will be repaired in the clothes show their awe of life, while eager to multiply.

Folk art in the same color has a special meaning, the West face, spreads and opera masks, five 
colors directly symbolize the task of character, identity and quality. Such as the drama of the public red face show people, including blue sky has always been the same black face, Cao Cao's face with white to the performance of these are all through the color to illustrate the various characteristics of the characters. In Chinese opera mask, red represents faithfulness and piety, white represents rape, blacks show controversy, the emotional expression of these colors and symbolic meaning in people's daily life, through memory, habits and experience come out, Yi Also known as the three primary colors of the nation, its national color is red, yellow and black, Yi clothing and lacquer in kind and so are with red, yellow, black three colors to express. In their eyes, the red meaning of joy, courage and fire in general enthusiasm, yellow that wealth, light and charm, black is expressed rigor, dignity and honor. Three colors with a reasonable, colorful, bright and yet stable.

Understanding and familiar with the folk art of color in the meaning of the meaning can make us more convenient to understand the folk art screen. In our country, red that festive, is the color of most people are very fond of, especially in the very festive days and occasions, the red is generally the main color. Paper cut a lot of use of the red, there are plans to intentionally, interested in auspicious, in the folk art screen can always see a variety of fame and auspicious shape and theme. A lot of themes in the folk widely circulated, every family knows that a lot of modeling has become a folk convention symbol, such art works are generally able to spread in the folk, timeless. The most important reason is that these symbols mean festive and auspicious, to bring people self-confidence and optimism of the emotions, giving the wisdom of the fun, so that people feel the joy and happiness, and ultimately lead people to life with more good longing.

Folk art works of happiness, good and auspicious pursuit of works through the form, content, shape and color, such as a comprehensive performance. Such as festive content performance will generally need to complete the composition of a balanced, works with a certain degree of decoration, giving a strong sense of the atmosphere, while the characters are also very vivid, with sturdy and tall image of the performance of men, with slim and graceful image Woman, at the same time generally will use bright and bright colors to express festive atmosphere. We are now seeing many of the gods of God's image is through the process of transformation from God to people, people will be through a lot of door god image shows the admiration of national heroes, but also show their desire for righteousness. The use of allegorical symbols in folk art is a good example of the longing for future life and the belief in justice and goodness.

The addition of auspicious meaning to the modern design, is to pass down the auspicious image given to the modern form of performance, in order to make our traditional culture in modern design can be performance and development. According to modern design ideas, will be added in the modern design elements of auspicious meaning. The essence of the ancient auspicious patterns extracted from the elements, with the new model for reorganization and design, while adding modern design ideas, in order to ensure the traditional artistic charm on the basis of, but also to show the characteristics of modern design and personality. In the modern design, it is to join the graphic elements of the profound meaning, to the inherent ideas and extension of the development, in order to show a profound cultural heritage and social, which is commonly used in modern design approach. A variety of traditional designs designed in auspicious play an important role in guiding modern design, in order to encourage modern designers in the process of innovation did not forget to play a good cultural traditions.

Looking ahead, Chinese modern design will be the ancient meaning of auspicious elements to join the modern design of the works is particularly small, so the meaning of auspicious elements should also be more widely quoted. It is not difficult to find that the use of a small amount of modern design in the auspicious works have shown its distinctive era and personality, leading people to respect and carry forward the traditional Chinese culture and art. The combination of auspicious elements and modern design ideas can show the uniqueness of traditional culture and art in our country so that traditional culture and arts can be inherited and developed through modern design. Now the rapid development of society has derived more new ideas and new ideas, at the same time because of the impact of foreign works of art, making our traditional culture and art continue to inherit and carry forward a variety of challenges. Regardless of the traditional culture 
and art of course not, and only blindly learn from and reference to the design of Western modernization will eventually make the design of the lack of national characteristics, so the heritage and carry forward the traditional plastic arts is necessary and necessary. Chinese modern design if you want to form its own unique characteristics, you need to be based on Chinese cultural background to design and creation, from our country in the international popular national characteristics of the works to find its success factors. The elements of auspiciousness must be one of the inevitable factors in the performance of our national culture. The elements of the auspicious elements make people feel the hope of life and hope for the good, and also show the fine traditional culture of our country to the people of the world. Such as the Phoenix TV logo, reference to the traditional culture of Tai Chi figure hi meet the graphics, hi meet auspicious meaning, its shape is based on the traditional Chinese culture in the design of the Phoenix, Phoenix and Phoenix's yin and yang intersection meaning the oriental and Western culture of benign interaction, but also implies the modern and traditional links between the thousands of strands is the tradition of fine cultural heritage.

\section{Conclusion}

Folk culture is the most common and most accustomed to the culture and the arts, which showed a profound cultural heritage. The symbolic symbols are produced from the people and are widely circulated in different classes of society. The passage of time for thousands of years has not diminished the art form of the symbolic symbol, but has inherited and developed it. At this stage, the symbolic symbol of the inheritance is more abundant the form of expression, directly show the masses of the art of imagination and creativity. Folk art symbolic symbols are through the folk activities to spread and develop, so most of the symbolic form of expression and connotation will reflect the different aspects of folk customs. Over time, part of the culture of folk culture gradually expressed through the moral, the spirit of the masses yearning and pursuit of the performance of the most incisive, so that if the full understanding of folk and familiar with, then read the meaning of folk art symbolic words to mention.

\section{References}

[1] Wang Shaoyong. Innovation - the development of folk art industry [J]. Management Manager .2017 (06)

[2] Ma Liangfen. Folk art modeling features and practical significance of learning[J]. Art evaluation .2017 (4): 8-9.

[3] Xia Jinzhong, Yang Wei, Huang Rong. Hubei folk art digital protection research [J]. Art Education .2017 (Z5)

[4] Du Xingxing. Folk art in the design of teaching in colleges and universities[J]. Art Education Research .2016 (23): 165-165.

[5] Yuan Min. Analysis of folk art resources in the use of art teaching [J]. Modern decoration (theory) .2016 (11) 